\title{
In the Field
}

National Cancer Institute

\section{Source}

National Cancer Institute. In the Field. NCI Thesaurus. Code C102650.

A setting outside the clinic or a comparable health care facility, e.g., a doctor's office, the subject's home or workplace, a school, a public park, or a restaurant. 